\title{
Monitoring sexual behaviour in general populations: a synthesis of lessons of the past decade
}

\author{
J Cleland, J T Boerma, M Carael, S S Weir
}

Sex Transm Infect 2004;80(Suppl II):ii1-ii7. doi: 10.1136/sti.2004.013151

This supplement contains selected papers from a workshop on the measurement of sexual behaviour in the era of HIV/ AIDS held at the London School of Hygiene and Tropical Medicine in September 2003. The focus was on low and middle income countries, where the majority of HIV infections occur. The motive for holding such a meeting is easy to discern. As the AIDS pandemic continues to spread and as prevention programmes are scaling up, the need to monitor trends in sexual risk behaviours becomes ever more pressing. Behavioural data are an essential complement to biological evidence of changes in HIV prevalence or incidence. Biological evidence, though indispensable, is by itself insufficient for policy and programme guidance. AIDS control programmes need to be based on monitoring of not only trends in infections but also of trends in those behaviours that underlie epidemic curtailment or further spread.

See end of article for authors' affiliations

Correspondence to:

Correspondence to:
Dr J G Cleland, Centre for Population Studies, London School of Hygiene \&

Tropical Medicine, 49-51 Bedford Square, London WC1B 3DP, UK;

john.cleland@|shtm.ac.uk

Accepted for publication 27 September 2004
O ne key lesson of the past decade is that the links between patterns of sexual behaviour in a population and rates of spread of HIV are immensely variable and complex. ${ }^{1}$ They vary between countries and evolve as epidemics mature. Powerful biological cofactors, such as ulcerating infections of the genital organs and circumcision of men, mediate and may obfuscate the effects of behaviour on HIV transmission. AIDS related mortality may dilute the relation between behaviour and infection. Aral's paper in this supplement well illustrates some of these complexities [see page ii8]. ${ }^{2}$ Further complications arise from the fact that in some populations differences in the spread of HIV can be explained by non-sexual modes of transmission, notably through sharing of needles and syringes by injecting drug users. Current evidence indicates that transmission associated with medical care plays a relatively minor role in generalised HIV/AIDS epidemics. ${ }^{3}$ but even in these epidemics we still do not fully understand why HIV spreads or declines so quickly in some settings and relatively slowly in others. Thus far behavioural data have had relatively weak explanatory power for elucidation of cross national differences. We shall argue below, however, that their power to make sense of trends in HIV within particular settings is much stronger.

Several methodological reviews of research into sexual behaviour have been published in the past decade or so. ${ }^{4-10}$ Most have acknowledged that the validity and reliability (or repeatability) of behavioural self-reports may not be high, as is also true for other sensitive topics. Many have expressed scepticism that the dominant mode of data collection-structured face to face interviews-is the most effective way to gather high quality information and have urged the use of alternative or complementary methods. This is a central issue to which we will return. Other commonly made points include the need for high, and therefore repeatable, standards of study execution, including intensive interviewer training, careful translation into local languages of such terms as sexual intercourse and sexual partners, and attention to participation bias. The need for continued methodological research has been stressed repeatedly. We agree with all these points. Poorly designed, hastily executed studies do more harm than good. But we will say little more about the need for high quality, as no purpose would be served in further reiteration.

Rather than attempt to synthesise all of the papers in this supplement, the main focus of this introductory paper is on monitoring sexual behaviour in general populations of low and middle income countries, thus defining three key boundaries to its scope. The first element of this focus-monitoring-refers to repeated measurement over time of indicators that inform policy makers on progress towards HIV prevention goals of reducing sexual risk behaviour. Monitoring needs to be distinguished from aetiological studies and from evaluation of specific interventions, both of which have very different monitoring demands in terms of the type of information required.

The second element of the focus-the restriction to general populations, including young people-is not intended to belittle the contribution of surveillance of high risk groups or venues. On the contrary, we accept without question the conventional wisdom that biological and behavioural monitoring in subpopulations that are particularly vulnerable to HIV infection are more valuable in low level and concentrated epidemic settings than monitoring of behaviour in general populations. We also acknowledge that the monitoring of behaviours in groups with higher levels of risk behaviours remains important in generalised epidemics. Nor is the topic neglected

Abbreviations: ACASI, audio computer assisted selfinterview; BSS, Behavioural Surveillance Survey; CASI, computer assisted self-interview; DHS, Demographic and Health Surveys; FFI, face to face interview; $S A Q$, selfadministered questionnaire. 
in this supplement. Recent advances in sampling and measurement, drawing largely on surveillance of high risk groups in Asia, are summarised [see page ii57]. ${ }^{11}$ The feasibility and utility of repeated surveys among the clientele of high risk venues such as bars and clubs is demonstrated [see page ii63]. ${ }^{12}$ A third paper shows that it is possible, at least in some settings, to achieve high retention rates in cohort studies of high risk groups, the example being female bar workers in Tanzania, a particularly vulnerable group [see page ii69]. ${ }^{13}$ Together these three papers support the view that more striking and imaginative advances in research design and methods have been made in the study of special groups than in the study of general populations.

The third element of the focus of the paper, restriction to low and middle income countries, reflects the fact that over $90 \%$ of HIV infections take place in these populations. The methodological challenges are also greater: the range of possible data collection modes is narrowed by variable literacy levels, and problems of response validity are more serious because of social desirability biases, stemming from more restrictive codes of permissible sexual behaviour than in North America or Europe.

The purpose of this paper is to distil the main lessons from the workshop presentations and from the published literature. The discussion is organised in the form of answers to the following (deceptively simple) questions. What should be measured? In which populations? How should the measurements be made? How trustworthy are the measures?

\section{WHAT SHOULD BE MEASURED?}

\section{The role of indicators}

The prime purpose of indicators is to permit the monitoring of progress towards policy and programme goals. Ideally, indicators should be simple to measure and easy to communicate to a non-scientific audience. They should measure forms of behaviour that are amenable to change. They should mirror precisely and unambiguously key programme goals. They should have high reliability and validity.

Monitoring of major international initiatives often focuses on a limited set of indicators. In the case of HIV, these include the Millennium Development Goals (which have one sexual behaviour indicator: condom use at last sex with a higher risk partner) and the goals set at the 2001 United Nations General Assembly Special Session (UNGASS) on AIDS. The list of UNAIDS core behavioural indicators relevant to the total adult population and to young people are listed in table 1 of Slaymaker's paper in this supplement [see page iil3]. ${ }^{14}$ The rationale for most of the indicators lies in the distinction between presumptively lower risk sexual partners (spouses or cohabiting partners) and higher risk, non-cohabiting partners, and between condom use and nonuse at most recent coital act with a higher risk partner. The relevance for disease transmission of these indicators varies by setting and epidemic phase. The match between indicators and HIV epidemiology is usually closest in the early and mid phases of generalised epidemics. In mature generalised epidemics, where an appreciable proportion of cohabiting couples are HIV discordant, transmission between cohabiting partners will make a large contribution to HIV incidence, thus undermining the equation of marital sex with low risk. ${ }^{15-17}$ Conversely in low level and concentrated epidemics, the sexual conduct of the general population will be less relevant. Nevertheless, the UNAIDS core behavioural indicators correspond closely to the broad thrust of HIV prevention efforts aimed at the general population, and thus maintain their practical relevance regardless of epidemiological setting. Recent evidence shows that the behaviours represented by indicators are amenable to change. They are conceptually simple and relatively easy to measure. There is no reason to believe that their validity or reliability is lower than alternative measures. In view of the amount of expert input into their development it is perhaps not surprising that they stand up well to critical scrutiny.

Three important caveats about the UNAIDS indicators are noted in Slaymaker's paper. ${ }^{14}$ Firstly, the nature and duration of non-cohabiting sexual relationships vary markedly across countries, thus complicating the interpretation of crossnational differences in indicator values. Secondly, it can be misleading to interpret trends in a single indicator without assessing possible concomitant trends in related indicators. For instance, interpretation of trends in the proportion of sexually active individuals reporting sex with a higher risk partner in the past year needs to take into account possible trends in primary or secondary abstinence that affect the size of the denominator. Similarly, trends in condom use need to be interpreted in conjunction with changes in the denominator, namely the proportion reporting a higher risk sexual partner. Because of these problems, a composite indicatorthe proportion of all adults who had a higher risk partner but did not use condoms at the most recent sex act-might be preferable to the existing indicators. The third caveat concerns the precision of estimates for rarely reported forms of risk behaviour. The example considered by Slaymaker is the reporting of commercial sex by men and condom use on the most recent occasion. Quite apart from measurement problems (acute in societies where exchange of money or gifts is a common element in sexual courtships), the confidence intervals of estimates tend to be very wide, thus making it impossible to detect statistically significant changes in behaviour unless such changes are very large.

In our view, the main conceptual defect of the UNAIDS indicators concerns condom use. Clearly, condom use by individuals who have frequent sex with several non-cohabiting partners is of greater epidemiological significance than use by those who have infrequent sex with only one such partner. The UNAIDS indicators-variants of condom use at most recent coital act during the last 12 months-attach equal weight to individuals regardless of number of partners and coital frequency, and thus fail to capture this important dimension. ${ }^{18}$ Ideally the indicators should be stratified by number of partners reported and weighted by the date of, or recency of, last coitus, thereby permitting an analysis of trends that takes into account both the extent of sexual mixing and recency-a powerful surrogate for frequency of intercourse. ${ }^{19}$ Alternatively, survey analyses should be limited to acts reported within the last three months, or for an even shorter recall period, but a limitation of this strategy is that numbers may be too small to derive estimates with adequate precision.

Age at first sex is one of the UNAIDS indicators for young people and one that is attracting great attention as interventions funded by the United States increasingly highlight sexual abstinence as a prevention priority. A paper in this supplement shows that most analyses of this indicator have not made full use of the data and that survival analysis is required to derive robust estimates [see page ii28]. ${ }^{20}$ When data from successive surveys are available, the opportunity should be taken to assess whether changes in reporting bias have occurred over time and whether trends have been thus distorted. The authors reach important conclusions: the upward trends in age at sexual debut in Uganda and Kenya appear valid; conversely the atypically old ages at debut and limited exposure to premarital sex reported in Zimbabwe appear implausible in the light of HIV surveillance data. 


\section{Beyond indicators}

The length of interview is only one factor affecting the costs of a population survey. Partly for this reason nearly all surveys that address HIV risk behaviour go well beyond the core UNAIDS indicators and this tendency holds true for the instruments promulgated by the two main survey programmes: Behavioural Surveillance Surveys (BSS) orchestrated by Family Health International and the Demographic and Health Surveys (DHS) of ORC-Macro Incorporated.

The most obvious way to enhance the epidemiological value of survey data on sexual behaviour beyond the standard indicators is to collect partner-specific details. The BSS approach is to elicit information about the most recent of each (if any) of three types of partner: spouse or cohabitee, commercial, and other non-regular. For each type of partner, coital frequency in last 30 days and condom use at most recent coitus is ascertained, together with frequency of condom use (in the form of a Likert scale) in the past 12 months with all such partners. In contrast, most DHS obtain details about the most recent two or three partners in the past year, regardless of type of partner. For all partners, duration and nature of relationship, age of the partner, use of condoms, and contraception at most recent coitus are ascertained. For the most recent partner only, time elapsed since last intercourse is obtained. In the DHS, a separate question is asked of men about recency of intercourse with a commercial sex partner and whether a condom was used on the last occasion.

By collecting rather more information about each partner the DHS comes closer than BSS to specialist instruments designed for intensive study of sexual networks. ${ }^{21}$ With three simple additions, the value of the DHS approach would be appreciably raised. The number of partnerships needs to be routinely increased to three, particularly in surveys of men. A question on whether recent partnerships are still continuing or not would permit more robust analyses of concurrent relationships and questions on time elapsed since last coitus with all partners (rather than just the most recent one) would enhance the utility of the condom use information.

In most populations, eliciting details about more than three sexual partners is probably not worthwhile because typically less than $5 \%$ of men report more than this number in the past year. Moreover the quality of information may be eroded because of respondent and interviewer fatigue. ${ }^{22}$ However, if the recent tendency to over-sample population strata with high levels of sexual mixing continues as, for instance, in the Kazakhstan DHS which over-sampled urban men, ${ }^{12}$ an extension beyond three partners might be justified. An alternative, less demanding approach would be to add a question to establish how many of all partners in the past year were new partners, thereby providing an estimate of the rate of partner acquisition

Another advantage of DHS over surveys more narrowly focussed on HIV prevention is the extensive information collected on fertility control motivations and contraception. Contraceptive practice has risen steeply in the countries of East and Southern Africa where HIV epidemics are most severe. As epidemics mature, the proportion of all HIV infections that occur within marital and cohabiting partnerships increases and the proportion of all such couples who are HIV discordant can be as high as $20 \%{ }^{23}{ }^{24}$ The protective needs of cohabiting couples have been overshadowed by the emphasis on condom use with non-marital partners but they are destined to become of increasing importance, particularly if the use of HIV testing services increases among cohabiting couples. Especially in the most severely affected countries in southern Africa, where at least one in six adults are HIV infected, intramarital HIV transmission may be one of the major reasons why no decline in HIV incidence or prevalence has been observed in recent years.

For most married and cohabiting couples, reproduction is a central concern that has huge potential implications for condom use. Very little is known about the interplay of reproductive and HIV prevention motives, partly because condom use within marriage, though increasing, is still so low. A strong desire to have a child soon is bound to act as a major deterrent to condom use. The effect of a strong desire to avoid future childbearing is less easy to predict. In so far as condoms are regarded as an effective method of dual protection, it should be conducive to their use. However, if a strong fertility regulation motive leads to a preference for highly effective non-barrier contraceptive methods which in turn makes more difficult the negotiation of condom use, then the effect might be negative. The key point of this discussion for the scope of future sexual behaviour surveys is that the protective needs and behaviour of married and cohabiting couples should not be overlooked and that improved understanding of trends in their behaviour must include consideration of reproductive motives and contraceptive behaviour.

\section{IN WHICH STUDY POPULATIONS SHOULD INDICATORS BE MEASURED?}

As this paper focuses on general population surveys we will not consider criteria for selecting high risk or bridging populations. Discussion will be limited to the more restricted range of options concerning the definition and sampling of general populations. The main options relate to age boundaries, sampling of both men and women or one sex only, and linking behavioural monitoring more closely to biomedical monitoring by conducting population surveys in the catchment areas of sentinel surveillance clinics.

Self-reported sexual risk behaviour typically declines from around the age of 30 years. It is also true that the majority of HIV infections and other STIs in heterosexual epidemics occur among those below this age. When funds for behavioural monitoring are limited, the restriction of samples to the age band 15-29 years, or 15-24 years, thus represents good value for money. It is a common strategy, as in the Young Adult Reproductive Health Surveys run by the Centers for Disease Control and in India's very large 2001 National Behavioural Surveillance Survey. ${ }^{25}$ Any further narrowing of the age band, to 15-19 year olds for instance, or lowering the age boundary to include those aged $10-14$ years is inadvisable. There are sound a priori reasons for expecting the validity of sexual behaviour reports of young teenagers to be particularly low, because of the strong social sanctions against early sexual activity in many societies and the clandestine nature of teenage sexual relationships. The empirical evidence, albeit very limited, supports this expectation. The validity and reliability of reported sexual experience among school students has been found to be particularly low in Tanzania and Zimbabwe [see page ii49]. ${ }^{26}{ }^{27}$ An analysis of trends in premarital sex among young women in Colombia and Peru concluded that respondents who had become sexually active very recently were especially likely to conceal their sexual status, ${ }^{28}$ and the evaluation of trends in reported age at first sex in this supplement casts doubt on their validity in some countries. ${ }^{20}$ Moreover, antenatal clinic based surveillance systems rarely find HIV infected pregnant women below the age of 15, and in virtually all community studies that include HIV testing of 13 and 14 year olds prevalence has been very low. ${ }^{2}$

The vast majority of sexual behaviour surveys include both men and women. For the multipurpose DHS, women are the prime respondents and typically only subsamples of men are taken. For surveys dedicated to HIV monitoring, such as BSS, 
men and women are usually sampled in equal number. Both strategies need to be challenged. One of the most striking and consistent features of sexual behaviour surveys in low and middle income countries is the huge gulf between the reports of men and women, well illustrated by a paper in this supplement [see page ii22]. ${ }^{29}$ Moreover the accumulated evidence shows beyond reasonable doubt that the main reason is the greater reluctance of women than men to report non-marital sexual partnerships. Evidence to support this verdict comes from several sources: biomedical validation of self-reported sexual experience, which usually shows higher seropositivity among self-reported female than male virgins; ${ }^{30}$ studies that show that HIV positive wives constitute a higher proportion of all HIV discordant couples than might be expected from behavioural self-reports; ${ }^{15}$ the greater sensitivity of women's reports to mode of data collection [see page ii36], ${ }^{31}$ and a unique census of sexual partnerships in Kisesa ward, Tanzania. ${ }^{32}$

One possible implication of widespread underreporting of non-marital sex by women for sexual behaviour monitoring is to focus attention on men's reports. However, this reaction must be balanced against other considerations. The gradient in HIV seropositivity with increasing number of non-marital partners tends to be steeper for women than men. ${ }^{33}$ Men's reports may be less consistent than women's $\mathrm{s}^{34}$ and the ever present danger of exaggeration of non-marital sex by men, particularly young single men, needs to be acknowledged. Women provide more reliable reports than men on contraceptive use, not least because most methods are under their control. Household surveys of men are logistically difficult because they are contactable at home less often than women and response rates are lower. Most importantly, to the extent that response bias remains constant, trends in women's reported sexual behaviour may be dependable.

Nevertheless, when funds for monitoring are tight and difficult choices have to be taken, it makes much sense to focus mainly, or even exclusively, on surveys of men. This recommendation applies with most force in many Asian countries, where sanctions against non-marital sexual activity by women tend to be strongest. In the 2000 Cambodian DHS, only $0.3 \%$ of married women reported more than one sexual partner in the past 12 months. ${ }^{35}$ In the 2001 Indian BSS, only 2\% of women aged 15-24 years reported a non-marital partner in the past year. ${ }^{25}$ These very low estimates make the detection of trends impractical. The recommendation applies with moderate force in Latin America and East and Southern Africa and least in West Africa where the gender gap in sexual behaviour reporting is less pronounced.

It has been suggested that sample surveys of populations in catchment areas of antenatal clinics that are used for surveillance would provide greater ability to link biological and behavioural trends. ${ }^{36}$ Practical experience however shows that such approaches are more costly and logistically complicated than investing in careful documentation of trends in behaviour through high quality surveys based on representative samples. ${ }^{37}$ A more useful strategy would be to over sample geographic areas of particular importance, as was done in the capital city of Kazakhstan in the most recent DHS, so that indicators are obtained for subnational areas of interest in addition to national indicators.

\section{HOW SHOULD MEASUREMENT BE MADE?}

Justified scepticism that conventional structured face to face interviews (FFIs) are the most appropriate method for eliciting sensitive information such as non-marital sex has led to a substantial methodological literature that compares results obtained by different data capture modes. ${ }^{38-46}$ Two contrasting alternatives to FFIs have been widely used. The first attempts to get closer to respondents and erode barriers to disclosure by gaining their trust. This aim is achieved most commonly by unstructured, often repeated, interviews and less commonly by the ethnographic technique of prolonged participation in the study population. The second attempts the opposite by reducing or eliminating interaction between data gatherer and subject; the main techniques here include self-administered questionnaires (SAQs) computer assisted self-interviews (CASIs) and audio computer assisted selfinterviews (ACASIs).

Four papers in this supplement contribute to the debate on data capture methodology. A review of trends among young people in the United States concludes that ACASI sometimes results in higher disclosure of sensitive behaviour than alternatives but not always [see page ii74]. ${ }^{47}$ A study of young women in Western Kenya demonstrated that ACASI yielded a very different profile of sexual conduct than FFIs or SAQs [see page ii43]. ${ }^{48}$ In Zimbabwe, an ingenious ballot box procedure resulted in greater reporting of risk behaviours than FFIs, though the difference in results obtained by the two methods in a longitudinal study narrowed over time. ${ }^{31}$ In a study of young teenagers in Tanzania little systematic difference was found in response between FFIs and a form of assisted SAQ where, because of marginal literacy, the questions were read out to groups of school students, but evidence of much higher levels of sexual activity were revealed by in-depth interviews and participatory methods. ${ }^{26}$

The experiences reported in this supplement are consistent with the wider body of evidence that alternatives to FFIs often yield higher and more plausible estimates of nonmarital sex but this apparent superiority is not guaranteed. Unfortunately they are rarely appropriate for general population surveys in low and middle income countries. In-depth interviews and participatory methods are a valuable complement to large-scale surveys but no substitute for them in terms of monitoring trends. Other methods, apart from ACASI, require reasonable literacy and often yield higher levels of item non-response and inconsistency of response than conventional interviews. Typically, questionnaires need to be short and simple in structure. In principle, ACASI overcomes most of these defects (though item non-response may be high), ${ }^{48}$ but its cost would probably be too great for large surveys and it remains extremely doubtful whether it is appropriate for populations unfamiliar with the technology. Even ACASI does not satisfactorily address the danger that respondents may not fully understand the terms used in sexual behaviour surveys. In the United States less educated respondents found the term "vaginal intercourse" difficult to understand and such respondents tended to give negative answers. ${ }^{49}$ In the linguistically heterogeneous countries of Africa, incomprehension of terms, for instance those describing different types of sexual partner or sexual abstinence, is likely be a greater problem than in the United States and can only be overcome by skilful interpersonal interviewing. To sum up, we see no realistic alternatives to FFIs for sexual behaviour monitoring in most countries of Africa, Asia, and Latin America.

As noted earlier, two survey programmes both using conventional FFIs dominate the domain of sexual behaviour monitoring: BSS and DHS. The BSS is dedicated to HIV related monitoring and is presumably introduced to respondents as such. The topic of sexual partnerships comes early in the interview, after only 17 questions on background characteristics and marriage. By comparison, explicitly sexual matters in DHS are raised only after lengthy series of questions on background, reproduction, and contraception (plus child health for female respondents). Does this marked contrast between the two types of survey influence responses on sexual behaviour? A priori considerations suggest that the 
DHS approach might be preferable because the interviewer has more opportunity to build rapport before broaching sensitive topics, and because the topics of sex, condoms, and HIV may be less threatening when embedded in a range of other topics. The evidence is very limited. A methodological study in Uganda found little difference in reported sexual risk behaviour when results from short and long questionnaires were compared. ${ }^{50}$ However the analysis of trends in Zambia in this supplement found much higher levels of reported nonmarital sexual partnerships in successive DHSs than in successive sexual behaviour surveys that used a shorter more focussed questionnaire similar to BSS. $^{51}$ Similarly, DHS yielded more disclosure of risk behaviour in the cities Cotonou, Yaoundé, Ndola, and Kisumu than surveys that focussed more narrowly on sexual behaviour. ${ }^{30}$

Although it is clearly premature to draw firm conclusions about the possible superiority of multipurpose over single purpose instruments, this issue has immense practical importance for sexual behaviour monitoring. Methodological work to confirm or refute the results from Zambia and the four city study is an urgent priority.

Little methodological work on questionnaire design for sexual behaviour surveys has been published, and the papers in this supplement make only a modest contribution. Among the key issues are the deliberate use of leading rather than neutral questions and how best to obtain frequency measures of number of partners, coitus, and condom use, together with the related issue of recall bias and reference periods.

With regard to leading questions, Curtis and Sutherland note the potentially crucial change between earlier DHS, which asked single respondents whether they had ever had sexual intercourse, and more recent DHS, which pose an alternative, leading question on age at first sexual intercourse, thereby placing the burden of denial on the respondent. ${ }^{29}$ Surprisingly, perhaps, this change made no major impact on the reporting of premarital sex. Very different lessons can be drawn from the study in Western Kenya reported in this supplement. ${ }^{48}$ Regardless of their answer to an initial question on whether they had ever experienced sexual intercourse, single young women were asked about sexual intercourse with specific types of partner (for example, relative or stranger) and about coerced sex. With ACASI, but not with FFIs, many respondents who had denied any experience of sexual intercourse subsequently reported sex with specific types of partner or coerced sex. The consistency of FFI results is probably attributable to interviewers who, having heard the initial global denial, may have asked subsequent questions in a cursory manner that invited negative responses. The ACASI results are more intriguing and raise the possibility that, even in FFI surveys, a short series of questions about sexual experience with specific types of partner might result in greater disclosure than a global question on sexual experience. Such an approach might also enhance reporting of number of lifetime sexual partners and number in the past 12 months. Assessment of this possibility is a high priority for methodological investigation.

An extensive literature exists on the measurement of frequency of coitus and condom use, though most studies are based on data from the United States and other industrialised countries. In 1994 Sheeran and Abraham were able to locate 72 studies that assessed condom use in the context of HIV prevention and the number must have risen greatly since that time. ${ }^{7}$ For the purposes of this paper the key issue is whether or not sexual behaviour surveys should routinely go beyond the collection of simple information on recency of coitus with specified partners and condom use on that occasion by the addition of more detailed measures of frequency. For monitoring purposes at the level of populations, the simple approach is adequate. This judgement is based on the following considerations. Strong correlations have been found between recency of coitus and frequency in the past four weeks and a method for deriving coital frequency from time elapsed since last coitus has been proposed, though more work needs to be done on the underlying assumptions. ${ }^{195253}$ The reliability of recency reports appears to be high. ${ }^{54}$ Recall of behaviour, such as condom use, is acknowledged to be less challenging to respondents when anchored to a specific event than when the requirement is to aggregate behaviour over a specified reference period and may be less prone to social desirability bias..$^{56}$ And, finally, use of condoms at last sexual event appears to be a reasonable proxy for consistent use, as the two measures have been found to be highly correlated both in cross sectional and prospective studies..$^{57} 58$

Of course, in more intensive studies of sexual behaviour, particularly those that seek to characterise the behaviour of individuals rather than obtain population level indicators, the last event approach has severe limitations and direct measures of frequency are highly desirable. ${ }^{59}$ In cross sectional surveys, however, recall problems pose an almost insurmountable obstacle to the accuracy of reports. For respondents who have had intercourse with a specific partner in the recent past, it is feasible to obtain a measure of frequency in the past four weeks together with measures of consistency of condom use, though heaping of responses on four, eight, and 12 coital acts is often encountered, indicating that respondents tend to formulate their answers in terms of one week and multiply by four. ${ }^{60}$ Shortening the recall period to one week would enhance accuracy of responses but could inevitably lead to a high proportion of zero answers.

Much more severe problems arise when coitus with a specified partner has not occurred recently. This does not apply only to unmarried respondents and to those who have secondary or more casual partners. Averaged across eight African DHS enquires, Brown found that $32 \%$ of married women reported no intercourse in the past four weeks. ${ }^{52}$ To obtain reasonably accurate retrospective estimates of frequency in these circumstances may be impossible, because of poor recall. Furthermore, questions that seek to elicit "usual behaviour" invite normative responses, and are known to be unreliable. ${ }^{61}$ In our view, prospective studies are essential for obtaining accurate frequency data that pertain to the less immediate past.

\section{HOW TRUSTWORTHY ARE MEASURES?}

When the international family planning movement gathered pace some 40 years ago, there was widespread and justified scepticism that survey respondents would be willing to report honestly on such personal matters as contraception and abortion. It is instructive to dwell briefly on the lessons learnt over past decades about the measurement of those behaviours in low and middle income countries. With regard to abortion the survey method has proved to be totally inadequate in most countries. This method of regulating fertility remains highly stigmatised and is often illegal in most circumstances. The barriers to disclosure have remained insurmountable. Instead, indirect methods based on hospital admissions, of necessity, have been used to derive estimates of the incidence of abortion. ${ }^{62}$

The story of the measurement of contraception is quite different. It is now widely, and correctly, accepted that well designed surveys usually yield reasonably valid estimates of contraceptive use. The reasons for this confidence have little to do with biomedical validation of reported behaviour. Rather it is based on the internal coherence of results, the plausibility of trends and a broad aggregate consistency of 
trends in contraceptive use with changes in levels of child bearing.

What verdict can be reached about the measurement of sexual behaviour in the context of HIV prevention? The evidence suggests that problems of disclosure are greater than for contraception but less than for abortion. Willingness to report non-marital sexual partnerships differs between men and women and varies between societies for reasons that are not fully understood. This consideration undermines the utility of surveys for intersocietal comparisons, a severe limitation.

With regard to trends, there are grounds for cautious optimism. Despite the complexities of the relation between behaviour and HIV transmission, we are unaware of any population in either the developing or developed world in which well substantiated declines in HIV incidence have not been accompanied by changes in reported behaviour that provide at least a partial explanation. Admittedly, only two low and middle income countries have thus far experienced major declines in HIV transmission-Uganda and Thailandbut in these two cases the behavioural and biological evidence is consistent. ${ }^{63-65}$ In Senegal, often cited as another HIV success story, behavioural and biological trend data are too sparse to make any judgement. ${ }^{66}$

Of equal importance is the absence of evidence of appreciable changes in behaviour in countries with no indications, thus far, of falls in HIV incidence. ${ }^{67}$ Zambia may prove to be an exception to this generalisation. Favourable trends in behaviour have been recorded without convincing evidence of any fall in HIV incidence. ${ }^{51}$

Even in populations where the level of reporting on nonmarital sex is suspect, trend data may be dependable and consistent with biological evidence. Analyses of DHS data for young single women in Latin America, for instance, yield a coherent and convincing picture of changes in the 1990s. ${ }^{28} 68$ Sexual activity before marriage increased, as did the use of condoms and other contraceptives. Pregnancy rates for all single women aged 15-24 years rose, because the decline in virginity was greater than the rise in contraceptive protection.

This relative confidence in the ability of successive surveys to provide reliable trend data, even when there are compelling reasons for believing that the level of non-marital sex is underreported, should not be overstated. Erratic and implausible trends in Ghana and Tanzania have been recorded by DHS. ${ }^{29}$ Furthermore, it is becoming clear that at least three surveys using very similar designs are necessary before even tentative conclusions should be drawn about trends. A further necessary precaution is to check that the composition of successive samples-in terms, for instance, of educational attainment and spatial distribution-did not change and to make appropriate adjustments if it did. ${ }^{2051}$

The single most important conclusion from this review is that reporting of sexual risk behaviour appears to be highly sensitive to survey designs. DHS results are unlikely to be comparable to BSS results, for instance. This lesson has huge implications for monitoring strategies because it implies that trends cannot be tracked by alternating between the very expensive but high quality and replicable DHS style of survey and cheaper, more focussed surveys such as BSS.

\section{ACKNOWLEDGEMENTS}

Comments on drafts of this paper by Susan Newcomer, Emma Slaymaker, and Basia Zaba were much appreciated.

\section{CONTRIBUTORS}

The scope of the paper was agreed by all authors. JC drafted the paper. JTB, MC and SSW commented on the draft and made amendments.

\section{Authors' affiliations}

J Cleland, Centre for Population Studies, London School of Hygiene and Tropical Medicine, London, UK

J T Boerma, World Health Organization, Geneva, Switzerland S S Weir, MEASURE Evaluation, University of North Carolina, Chapel Hill, NC, USA

M Carael, UNAIDS, Geneva, Switzerland

\section{REFERENCES}

1 Grassly NC, Garnett GP, Schwartlander B, et al. The effectiveness of HIV prevention and the epidemiological context. Bull World Health Organ 2001;79:1121-35.

2 Aral SO. Sexual risk behaviour and infection: epidemiological considerations. Sex Transm Infect 2004;80(Suppl II):ii8-12.

3 Schmid GP, Buvé A, Mugyenyi P, et al. Transmission of HIV-1 infection in subSaharan Africa and effect of elimination of unsafe injections. Lancet 2004;363:482-8.

4 Ankrah EM. AIDS: methodological problems in studying its prevention and spread. Soc Sci Med 1989;29:265-76.

5 Catania JA, Gibson DR, Chitwood DD, et al. Methodological problems in AIDS behaviour research: influences on measurement error and participation bias in studies of sex behaviour. Psychol Bull 1990;108:339-62.

6 Frank $\mathrm{O}$. International research on sexual behaviour and reproductive health: a brief review with reference to methodology. Annu Rev Sex Res 1994:5: 1-49.

7 Sheeran P, Abraham C. Measurement of condom use in 72 studies of HIVpreventive behaviour: a critical review. Patient Educ Couns 1994;24:199-216.

8 Huygens $P$, Kajura E, Seeley J, et al. Rethinking methods for the study of sexual behaviour. Soc Sci Med 1996;42:221-31.

9 Weinhardt LS, Forsyth AD, Carey MP, et al. Reliability and validity of selfreport measures of HIV-related sexual behavior: progress since 1990 and recommendations for research and practice. Arch Sex Behav 1998:27:155-80.

10 Fenton KA, Johnson AM, McManus S, et al. Measuring sexual behaviour: methodological challenges in survey research. Sex Transm Infect $2001 ; 77: 84-92$.

11 Mills S, Saidel T, Magnani R, et al. Surveillance and modelling of HIV, STI and risk behaviours in concentrated HIV epidemics. Sex Transm Infect 2004;80(Suppl II):ii57-62.

12 Weir SS, Tate JE, B Zhusupov B, et al. Where the action is: monitoring local trends in sexual behaviour. Sex Transm Infect 2004;80(Suppl II):ii63-8.

13 Hoffmann O, Zaba B, Wolff B, et al. Methodological lessons from a cohort study of high risk women in Tanzania. Sex Transm Infect 2004;80(Suppl II):ii69-73.

14 Slaymaker $E$. A critique of international indicators of sexual risk behaviour Sex Transm Infect 2004;80(Suppl II):ii 13-21.

15 Allen S, Meinzen-Derr J, Kautzman M, et al. Sexual behavior of HIVdiscordant couples after HIV counseling and testing. AIDS 2003;17:733-40.

16 Allen S, Londan C, Serufilia A, et al. Human immuno-deficiency virus infection in urban Rwanda. Demographic and behavioural correlates in a representative sample of childbearing women. JAMA 1991;266:1657-63.

17 Fylkenes K, Musonda RM, Kasumba K, et al. The HIV epidemic in Zambia: socio-demographic prevalence patterns and indications of trends among childbearing women. AIDS 1997;11:339-45.

18 Slaymaker E, Zaba B. Measurement of condom use as a risk factor for HIV infection. Reprod Health Matters 2003;11:174-84.

19 Leridon H. La fréquence des rapports sexuels. Données et analyses de cohérence. Population 1993;5:1381-408.

20 Zaba B, Pisani E, Slaymaker E, et al. Age at first sex: understanding recent trends in African demographic surveys. Sex Transm Infect 2004;80(Suppl II):ii28-35.

21 UNAIDS. Looking deeper into the HIV epidemic: a questionnaire for tracing sexual networks. Geneva: UNAIDS, 1998.

22 Carael M, Glynn JR, Lagarde E, et al. Sexual networks and HIV in four African populations: the use of standardised behavioural survey with biological markers. In: Morris M, ed. Network Epidemiology. Oxford: Oxford University Press, 2004:58-84

23 King R, Allen S, Seruflia A, et al. Voluntary confidential HIV testing for couples in Kigali, Rwanda. AIDS 1993;7:1393-94.

24 McKenna SL, Muyinda GK, Roth D, et al. Rapid HIV testing and counselling for voluntary testing centers in Africa. AIDS 1997;11(Suppl):S103-S110.

25 National AIDS Control Organisation (India),United Nations Children's Fund Knowledge, attitudes and practices of young adults (15-24 years): disaggregated data from the National Behavioural Surveillance Survey (2001). New Delhi: NACO and UNICEF, 2002.

26 Plummer ML, Ross DA, Wight D, et al. "A bit more truthful": the validity of adolescent sexual behaviour data collected in rural northern Tanzania using five methods. Sex Transm Infect 2004;80(Suppl II):ii49-56.

27 Cowan FM, Langhaug LF, Mashungupa GP, et al. School-based HIV prevention in Zimbabwe: feasibility and acceptability of evaluation trials using biological outcomes. AIDS 2002;16:1673-78.

28 Ali MM, Cleland J, Shah IH. Trends in reproductive behaviour among young single women in Colombia and Peru: 1985-99. Demography 2003:40:659-73.

29 Curtis SL, Sutherland EG, et al. Measuring sexual behaviour in the era of HIV/ AIDS: the experience of Demographic and Health Surveys and similar enquiries. Sex Transm Infect 2004;80(Suppl II):ii22-7. 
30 Buvé A, Lagarde E, Carael $M$, et al. Interpreting sexual behaviour data: validity issues in the multicentre study on factors determining the differential spread of HIV in four African cities. AIDS 2001;15(Suppl 4):S117-S126.

31 Gregson S, Mushati $P$, White $P$, et al. Informal confidential voting interview methods and temporal changes in reported sexual risk behaviour for HIV transmission in sub-Saharan Africa. Sex Transm Infect 2004;80(Suppl II):ii36-42.

32 Nnko S, Boerma JT, Urassa M, et al. Secretive females or swaggering males? An assessment of the quality of sexual partnership reporting in rural Tanzania. Soc Sci Med 2004;59:299-310.

33 Lagarde E, Congo Z, Meda N, et al. Epidemiology of HIV infection in urban Burkina Faso. Int J STD AIDS 2004;15:395-402.

34 Eggleston E, Leitch J, Jackson J. Consistency of self-reports of sexual activity among young adolescents in Jamaica. Int Fam Plann Persp 2000;26:79-83.

35 National Institute of Statistics, Directorate General for Health (Cambodia), ORC Macro. Cambodia Demographic and Health Survey 2000. Phnom Penh, Cambodia and Calverton, Maryland USA, 2001.

36 Rehle T, Lazzari S, Dallabetta G, et al. Second generation HIV surveillance: better data for decision-making. Bull World Health Organ 2004:82:121-7.

37 Zaba B, Slaymaker E, Urassa M, et al. The role of behavioural data in HIV surveillance. AIDS 2005 (in press).

38 Mclaws M, Oldenburg B, Ross MW, et al. Sexual behaviour in AIDS-related research: reliability and validity of recall and diary measures. J Sex Res 1990;27:265-81.

39 Enel C, Lagarde E, Pison G. The evaluation of surveys of sexual behaviour: a study of couples in rural Senegal. Health Transition Review 1994;4(Suppl): 111-24.

40 Tourangeau R, Smith TW. Asking sensitive questions: the impact of data collection mode, question format, and question context. Public Opin Q 1996;60:275-304.

41 Leigh BC, Gillmore MR, Morrison DM. Comparison of diary and retrospective measures for recording alcohol consumption and sexual activity. J Clin Epidemiol 1998;51:119-27.

42 Turner CF, Ku L, Rogers SM, et al. Adolescent sexual behavior, drug use, and violence: increased reporting with computer survey technology. Science 1998;280:867-73.

43 Gribble JN, Miller HG, Rogers SM, et al. Interview mode and measurement of sexual behaviours: methodological issues. J Sex Res 1999:36:16-24.

44 Ramjee G, Weber AE, Morar NS. Recording sexual behaviour:comparison of recall questionnaires with a coital diary. Sex Transm Dis 1999;26:374-80.

45 Gregson S, Zhuwau T, Ndlovu J, et al. Methods to reduce social desirability bias in sex surveys in low-development settings: experience from Zimbabwe. Sex Transm Dis 2002;29:568-75.

46 Mensch BS, Hewett PC, Erulkar AS. The reporting of sensitive behaviour by adolescents. Demography 2003;40:247-68.

47 Biddlecom A. Trends in sexual behaviours and infections among young persons in the United States. Sex Transm Infect 2004;80(Suppl II):ii74-9.

48 Hewett PC, Mensch BS, Erulkar AS. Consistency in the reporting of sexual behaviour by adolescent girls in Kenya: a comparison of interviewing methods. Sex Transm Infect 2004;80(Suppl II):ii43-8.

49 Binson D, Catania JA. Respondents' understanding of the words used in sexual behaviour questions. Public Opin Q 1998;62:190-208.
50 Konings $E$, Bantebya $G$, Carael $M$, et al. Validating population surveys for the measurement of HIV/STD prevention indicators. AIDS 1995;9:375-82.

51 Slaymaker E, Buckner B. Monitoring trends in sexual behaviour in Zambia, 1996-2003. Sex Transm Infect 2004;80(Suppl II):ii85-90.

52 Brown MS. Coitus, the proximate determinant of conception: inter-country variance in sub-Saharan Africa. J Biosoc Sci 2000;32:145-59.

53 Knodel J, Chayvoyan N. Coital activity among married Thai women. In:Proceedings of the Demographic and Health Surveys Conference, vol II. Columbia, Maryland, USA: IRC/Macro International Inc, 1991:925-46.

54 Becker S, Begum S. Reliability study of reporting of days since last sexual intercourse in Matlab, Bangladesh. J Biosoc Sci 1994;26:291-9.

55 Rietmeijer CA, Lansley A, Anderson J, et al. Developing standards in behavioural surveillance for HIV/STD prevention. AIDS Educ Prev $2001 ; 13: 268-78$

56 Catania JA, Dolcini MM, Leumann EO, et al. A response to "developing standards in behavioural surveillance of HIV/STD prevention". AIDS Educ Prev 2002; 14:343-7.

57 Lagarde E, Auvert B, Chege J, et al. Condom use and its association with HIV/ sexually transmitted diseases in four urban communities of sub-Saharan Africa. AIDS 2001;15(Suppl 4):S71-78.

58 Myer L, Mathews C, Little F. Measuring consistent condom use: a comparison of cross-sectional and prospective measurements in South Africa. Int J STD AIDS 2002; 13:62-3.

59 Weir SS, Roddy RE, Zekeng L, et al. Measuring condom use: asking "do you or don't you" isn't enough. AIDS Educ Prev 1998;10:293-302.

60 Blanc AK, Rutenberg N. Coitus and contraception - the utility of data on sexual intercourse for family-planning programs. Stud Fam Plann $1991 ; 22: 162-76$

61 Hornsby PP, Wilcox AJ. Validity of questionnaire information on frequency of coitus. Am J Epidemiol 1989;130:94-9.

62 World Health Organization. Unsafe abortion. Global and regional estimates of incidence of and mortality due to unsafe abortion with a listing of available country data. (WHO/RHT/MSM/97.16) World Health Organization; Division of Reproductive Health, Geneva, 1998.

63 Kilian AHD, Gregson S, Ndyanabangi B, et al. Reductions in risk behaviour provide the most consistent explanation for declining HIV-1 prevalence in Uganda. AIDS 1999;13:391-8.

64 Kamali A, Carpenter LM, Whitworth JAG, et al. Seven-year trends in HIV-1 infection rates and changes in sexual behaviour among adults in rural Uganda. AIDS 2000;14:427-34.

65 Nelson KE, Celentano DD, Eiumtrakol S, et al. Changes in sexual behaviour and decline in HIV infection among young men in Thailand. N Engl J Med 1996;335:297-303.

66 UNAIDS. Acting early to prevent AIDS: the case of Senegal. Geneva: UNAIDS, 1999.

67 Bessinger R, Akwara P, Halperin D. Sexual behaviour, HIV and fertility trends: a comparative analysis of six countries. Phase 1 of the $A B C$ study University of North Carolina, MEASURE Evaluation Project, 2003.

68 Ali MM, Cleland J. Sexual and reproductive behaviour among single women aged 15-24 in eight Latin American countries: a comparative analysis. Soc Sci Med 2005 (in press). 